\title{
Giấc mộng đêm giữa hè với hai quả mít và Black-Scholes PDE
}

\author{
Vương Quân Hoàng
}

Ngày 3 tháng 6 năm 2021

Hôm nay là sinh nhật con gái lớn, Thu Trang, đang trong những ngày cuối chương trình cao học tại Sciences Po Paris.

Những ngày này Hà Nội nóng như đổ lửa. Lúc trưa chắc hơn $40^{\circ} \mathrm{C}$, "nước như ai nấu chết cả cá cờ" (Trần Đăng Khoa [1]). Đến đêm mới dịu bớt.

Ngồi đếm lại thời gian trong âm nhạc thời Youtube, trôi lạc vào Giấc mộng đêm giữa hè của Mendelssohn (1809-1847). Thật lòng, lúc giữa đêm này, khúc nhạc ngắn Venetian Gondola của ông hợp hơn. Tưởng tượng ra tiếng mái chèo khua nước trong đêm, âm hưởng lãng đãng oi ả mong vài ngọn gió có hơi mát... Rất thích thú. Bản Op. 60 No. 6 của Mendelssohn có âm hưởng và cả độ dài khá gần với các Nocturne của Chopin, khoảng 3-4 phút.

Sở dĩ tôi chợt nảy ra thú vui nghe nhạc giữa đêm là vì hai quả mít.

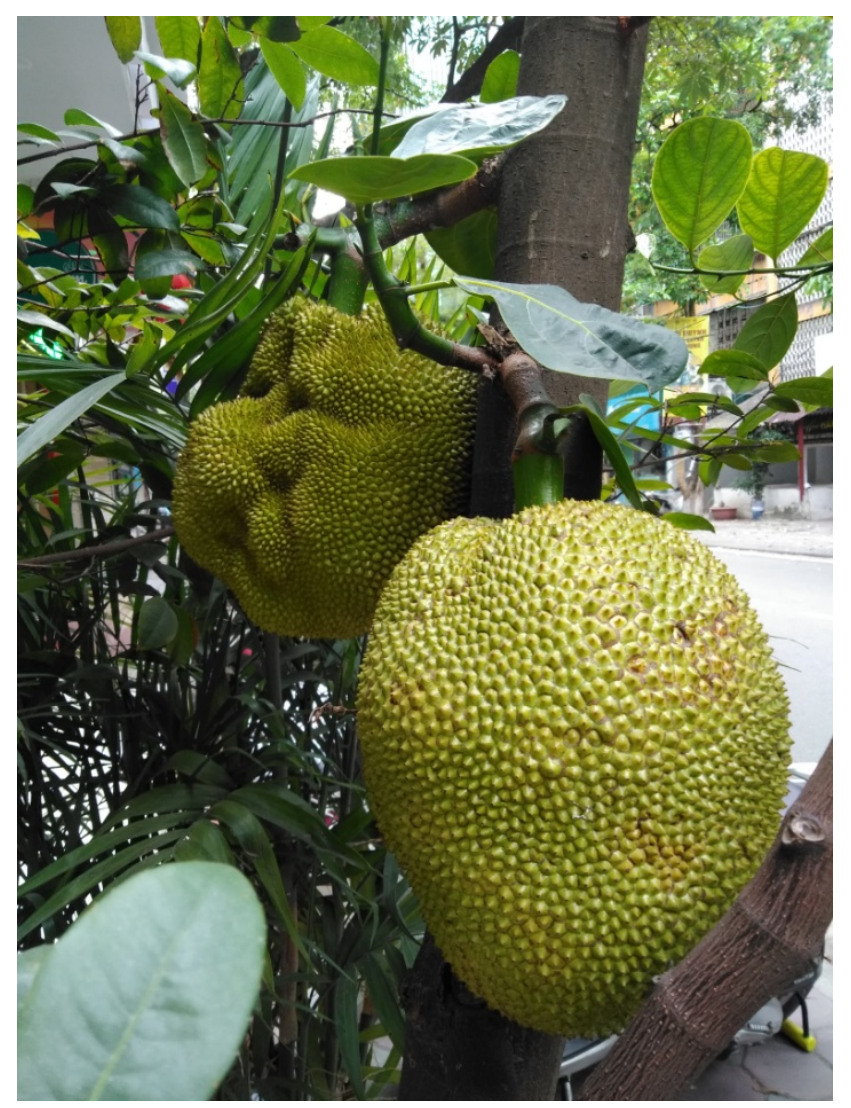


Hai quả mít mà mất 11 năm trồng cây, giữ gìn, mới cho quả. Lúc cuối tháng 3 quả đậu. Đâu chừng 20 quả, rồi mưa, gió, sâu... nay còn lại hai quả đã khá lớn. Da đã ngả dần màu vàng vài chỗ. Sẫm lại thành mầu nâu thì sẽ đến độ chín.

Lúc trước, gia đình tôi đã dành nhiều thời gian gây dựng vườn quê ở Kim Sơn, Sơn Tây, cách hồ Đồng Mô chừng 15 phút đi bộ. Trong vườn có 3 cây mít. Lúc đó mới trồng, hy vọng được thu hoạch. Nhưng nào có kịp thấy quả. Đến 2016, con gái lớn sang Pháp học, lại quay lại công việc ở Hà Nội trong chương trình làm việc mới, vậy là vườn quê bị bỏ bẵng.

Cái khu vườn ấy có một cái ao, sau một thời gian chăm sóc có rất nhiều cá và tôm sinh sôi nảy nở. Một vài chú ếch và chão chuộc ở đâu kéo tới. Thi thoảng lại có vài tổ vò vẽ xuất hiện.

Sơ sơ cũng khoảng chục gốc cây vối trồng rải rác khắp vườn. Có cây hồng bì già, trông khẳng khiu, nho nhỏ, nhưng cũng 50 tuổi. Quả thật sau này trồng mới biết, cây hồng bì trồng 7-8 năm mà thân nó mới bé tẹo. Tuy vậy, khoảng 6 cây sấu, trong đó có 3 cây già cỡ trăm năm mới thực gây ra sự thích thú. Nó nhắc tôi nhớ đến thời trẻ con, sống ở phố Trần Phú, Ba Đình, Hà Nội, một dẫy phố tiêu biểu của kiến trúc Pháp, và một hàng sấu chạy dài từ đường tầu sát Lý Nam Đế, đến Lê Trực. Mùa hè, trên cây sấu có vô số các bạn ve ngân nga thúc giục đám trẻ con ra khỏi nhà, đi chơi...

Thời kỳ ấy, những ngày về nằm ở vườn là được hưởng thú vui ngắm trăng khuya, nghe tiếng dế mà như Hàn Mặc Tử thốt lên trong Thức Khuya:

\section{Khóc giùm thân thế hoa rơi lệ \\ Buồn giúp công danh dế dạo đàn}

Rồi lại lặng lẽ nằm trên chõng tre nghe các khúc nocturne của Frédéric Chopin, Franz Listz, Felix Mendelssohn, v.v.. Thỉnh thoảng nghe văng vẳng tiếng chão chuộc oán than, tiếng cá quẫy nước, âm thanh của cánh ve (cũng có khi bọ xít) bay xèo qua lùm cây nhãn.

Đôi khi, lại có đoạn nhạc hay còn khớp với tiếng thiên nhiên chỉ có thể gọi là ngẫu nhiên, tới mức cực đoan, như tiếng chim đang ngủ thì bị giật mình kêu choe chóe, rồi lại tắt lịm giữa lùm cây. Một nốt nhạc kỳ quái không ai quy định, lúc nửa đêm.

Mới đó mà đã năm thứ 6 không còn thời gian với vườn quê. Hình ảnh đẹp quả là nằm ở đáy võng mạc. Rung động trọn vẹn thuộc về ký ức và hồi tưởng. Cơ chế của trí nhớ rất kỳ lạ. Khi nó truy xuất thông tin, 6 năm hay 16 năm có vẻ như không phải là khoảng cách, mà chỉ là sự kiện.

Khi nãy lục xem tài liệu, bắt gặp phương trình vi phân Black-Scholes. Thế là gần như ngay lập tức, thước phim năm 2001 hiện ra. Cũng là những đêm lẩm nhẩm bài Thức Khuya, nhưng 20 năm trước rồi. Là cái thời của bài Black-Scholes PDE [2]. Lúc ấy, tài chính và tính toán là một thế giới kỳ thú. Đó cũng là thời kỳ có thể mất nhiều đêm để viết các đoạn code $\mathrm{C}++$ cho một vài bài toán tài chính. Đôi khi rách việc, còn bỏ cả thời gian để bắt lỗi code của những đồng nghiệp khác. 
(Cũng phải nói, những say sưa tưởng như ngớ ngẩn một giai đoạn nào đó, lại tạo ra sự lý thú đủ hấp dẫn cho cả một thời kỳ dài lâu về sau, đầy ắp những công việc liên quan đến tính toán tài chính, cho người và cả cho mình [3-8].)

Khi ấy, vào lúc 20 năm trước thì Thu Trang mới 3 tuổi.

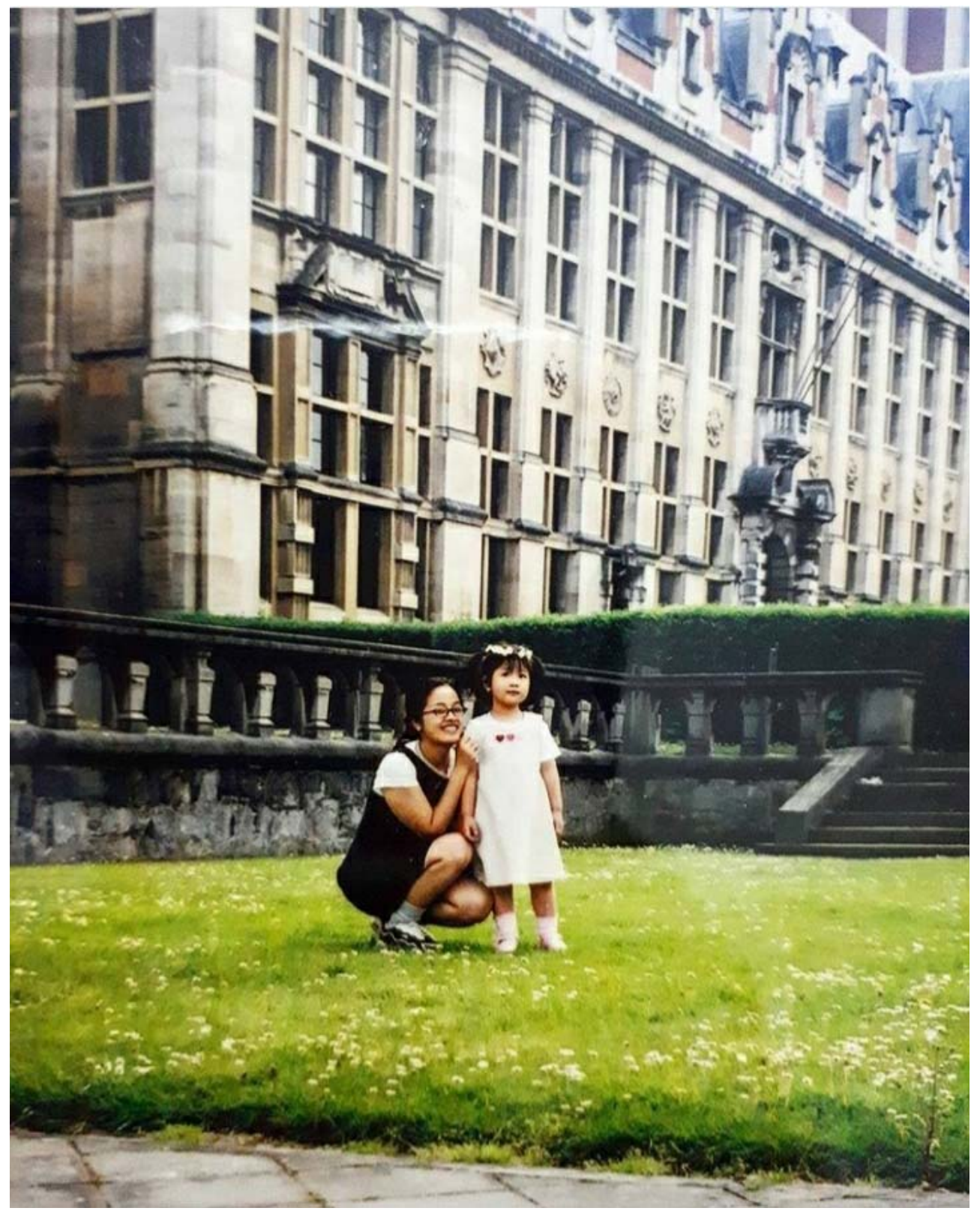

Thu Trang và mẹ, năm 2001, trước tòa nhà hành chính Université Libre de Bruxelles. Phía bên kia đường là Centre Emile Bernheim (21 Ave. F. D. Roosevelt, Bruxelles, Belgium). 
Bây giờ, thì tôi cũng đủ nhiều tuổi (còn gọi là "già") để bắt đầu ghi lại những quan sát cuộc đời bằng truyện "Ngụ ngôn bói cá" (https://osf.io/s53g9/), như để kể lại cho đám trẻ con. Khi mà làm được việc ấy, thì trẻ con trong nhà cũng đã lớn lên, đi học nơi xa xôi, và bắt đầu hành trình như ông cha xưa kia.

Giờ thì câu hỏi là, vậy 20 năm sau đây nữa sẽ ra sao.

Lẽ tự nhiên là chẳng thể có câu trả lời. Có những câu hỏi chỉ để khẳng định mình đã từng băn khoăn và không mong được giải đáp.

Còn nếu nói về mong ước, thì cái mộng ba sinh dệt ra cho việc nghiên cứu này qua đi, để sau ngoảnh lại khẽ tự bảo mình: Ngày ấy làm việc ấy đã xong, từ lâu lắm rồi.

Rồi lại có được những đêm nằm chõng tre, ngâm nga vài điệu cũ theo tiếng đàn của lũ dế, hay nghe chão chuộc uôm oạp mà thử đoán thời tiết ngày mai.

Giờ thì hiểu, làm được những việc bình thường như thế lại đáng gọi là phi thường!

Hà Nội, rạng sáng 3 tháng 6 năm 2021.

\section{Tài liệu tham khảo:}

[1] Khoa, T. Đ. (1968). Hạt gạo làng ta. Góc sân và khoảng trời. Nxb Văn nghệ, Hà Nội.

[2] Vuong, Q. H. (2001). Black-Scholes PDE: A finance application. International Conference on Differential Equations, Approximations and Applications, DEAA - 2001. Vietnam National University (December 15)

[3] Hoàng, V. Q. (2004). Hiệu ứng GARCH trên dãy lợi suất thị trường chứng khoán Việt Nam 2000-2003. Tạp chí Ứng dụng Toán học, 2(1), 15-30.

[4] Van Huu, N., Hoang, V. Q., \& Ngoc, T. M. (2005). Central limit theorem for functional of jump Markov processes. Vietnam Journal of Mathematics, 33(4), 443-461.

[5] Hoàng, V. Q., Hưng, Đ. G., Hữu, N. V., \& Ngọc, T. M. (2006). Phương pháp thống kê xây dựng mô hình định mức tín nhiệm khách hàng thể nhân. Tạp chi ứng dụng Toán học, 4(2), 1-16.

[6] Hữu, N. V., \& Hoàng, V. Q. (2007). Các phương pháp toán học trong tài chính. Nxb Đại học Quốc gia Hà Nội.

[7] Van Huu, N., \& Hoang, V. Q. (2007). On the martingale representation theorem and on approximate hedging a contingent claim in the minimum deviation square criterion. In: Some Topics in Industrial and Applied Mathematics (pp. 134-151). Singapore: World Scientific.

[8] Thao, H. T., \& Vuong, Q. H. (2015). A Merton model of credit risk with jumps. J. Stat. Appl. \& Probability Letters, 2(2), 97-103. 